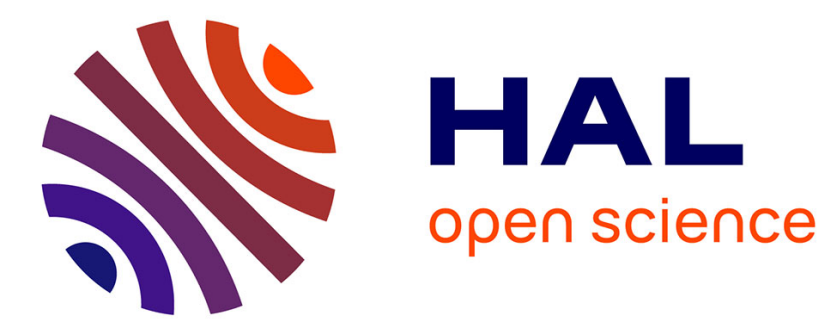

\title{
From plant and logistics control to multi-entreprise collaboration
}

Shimon Nof, Gérard Morel, Laszlo Monostori, Arturo Molina, Florin Filip

\section{To cite this version:}

Shimon Nof, Gérard Morel, Laszlo Monostori, Arturo Molina, Florin Filip. From plant and logistics control to multi-entreprise collaboration. IFAC Annual Reviews in Control, 2006, 30 (1), pp.55-68. hal-00092381

\section{HAL Id: hal-00092381 \\ https://hal.science/hal-00092381}

Submitted on 8 Sep 2006

HAL is a multi-disciplinary open access archive for the deposit and dissemination of scientific research documents, whether they are published or not. The documents may come from teaching and research institutions in France or abroad, or from public or private research centers.
L'archive ouverte pluridisciplinaire $\mathbf{H A L}$, est destinée au dépôt et à la diffusion de documents scientifiques de niveau recherche, publiés ou non, émanant des établissements d'enseignement et de recherche français ou étrangers, des laboratoires publics ou privés. 


\title{
FROM PLANT AND LOGISTICS CONTROL TO MULTI-ENTERPRISE COLLABORATION: Milestone report of the Manufacturing \& Logistics Systems Coordinating Committee
}

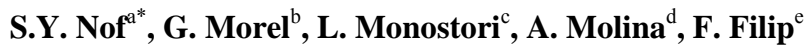 \\ ${ }^{a}$ School of Industrial Eng. Purdue Univ. 315 N. Grant St., West Lafayette, IN 47907-2023 USA \\ ${ }^{\mathrm{b}}$ Université Henri Poincaré, CRAN CNRS UMR 7039, Vandoeuvre-les-Nancy, France \\ ${ }^{c}$ Computer \& Automation Res. Inst. Hungarian academy of Sciences, Kende u. 13-17 H-1518 Budapest, \\ Hungary \\ ${ }^{\mathrm{d} S c h o o l ~ o f ~ E n g . ~ a n d ~ A r c h . ~ T e c . ~ d e ~ M o n t e r r e y, ~ A v . ~ E . ~ G a r z a ~ S a d a ~} 2501$ Sur Monterrey, N. León 64849 \\ Mexico \\ ${ }^{\mathrm{e}}$ Romanian Academy, Calea Victoriei 125, 71102 Bucharest, Romania \\ *Corresponding authornof@purdue.edu Tel. +1-765-494-5427 Fax: +1-765-494-1299
}

Abstract: Current and emerging manufacturing and logistics systems are posing new challenges and opportunities for the automation and control community. This milestone report describes the main problems, such as management of complexity, scalability, increasing costs, coordination, market-based resource allocation, and more. Recent accomplishments and trends are discussed: Control and automation techniques, manufacturing plant automation, collaborative control through integration and networking, and control methods applied to extended enterprises and large-scale critical infrastructure. Finally, forecasts are presented for the next generation manufacturing system; e-work; integration, coordination and collaboration; networked, distributed decision support (NDSS); and active middleware.

Keywords: Agents, Bio-Inspired Control, Collaborative Control, Complex Systems,
Coordination, Digital Enterprise, Distributed Manufacturing, Enterprise
Networks, Integration, Large-Scale Systems, Multi-Agent Control.

\section{INTRODUCTION AND SCOPE}

Emerging economies, social and political transitions, and new ways of doing business are changing the world dramatically. These trends suggest that the competitive environment for manufacturing enterprises will be significantly different than it has been. To be successful in tomorrow's more competitive climate, manufacturing enterprises will require significantly improved technological, managerial, and logistics capabilities. The acquisition of these capabilities represents a serious challenge facing manufacturing.

A new competitive environment for industrial products and services is emerging and is forcing a change in the way manufacturing enterprises are designed and managed. Competitive advantages in the new global economy will belong to supply enterprises that are capable of responding rapidly and smoothly to the demand for high quality and highly customized products, while maintaining their lean and just-in-time actions at costeffectiveness. Operating new competitive firms is becoming more difficult as product variety and options increase, product complexity increases, product life cycles shrink, and profit margins decrease. In addition, the capital costs of manufacturing technologies are extremely high. These factors require high productivity levels for labor, logistics and manufacturing facilities. There is also the need to create the next generation manufacturing systems with higher levels of flexibility, allowing these systems to respond as a component of enterprise networks in a timely manner to highly dynamic supply-and-demand networked markets. 
The many diverse functional challenges facing today's manufacturers can be briefly summarized as illustrated in Figure 1a; Automation, Management \& Control, Enterprise Integration \& Networking, and Large Scale Complexity. Increasingly, solutions for these challenges are now being developed, and encouraging trends are becoming evident, as illustrated in Figure 1b. This report describes the most significant challenges and the most promising emerging solutions for modern manufacturing systems.

[Insert Fig. 1 Here]

\section{CURRENT KEY PROBLEMS}

Manufacturing systems struggle with both traditional and new problems under increasing complexity, scalability stress, increasing costs, and changing environment, both business and legal. These problems involve uncertainties, need for rapid change, globalization challenges, need for cooperation and conflict resolution, coordination and scheduling, need for better and more realistic models, and need for more effective understanding and interaction between diverse models and markets. Manufacturing systems are expected to satisfy ever-increasing customer demand for more customized products at lower cost and better quality, while addressing recycling and environmental concerns, need for efficient reconfiguration, and challenges in accepting and absorbing new technological solutions, from nanotechnology sensors to wireless communication.

\subsection{Management of complexity, change and uncertainties in manufacturing}

Manufacturing systems operate in a fast changing environment full of uncertainties. Increasing complexity is another significant challenge in many production processes. One of the recent areas of research is related to the globalization of production. Production networks (PNs) are formed from independent companies, collaborating by shared information, skills, resources, and driven by the common goal of exploiting market opportunities.

The concept of the digital enterprise, i.e. the mapping of the key processes of an enterprise to digital structures by means of information and communication technologies (ICT) gives a unique way of managing the above problems. By using recent advances of ICT, theoretically, all the important production-related information is available and manageable in a controlled, user-dependent way (Kopacek et al., 2005, Ishii et al., 2005).

Management, the optimal or near optimal utilization of this huge amount of information, however, cannot be imagined without the effective application of the methods and tools of artificial intelligence (AI) (Monostori, 2003). In certain situations, more specifically, the methods also require machine learning (ML) techniques (Morel and Grabot, 2003).

The development and application of intelligent decision support systems can help enterprises cope with problems of uncertainty and complexity, to increase efficiency, join competitively in production networks, and improve the scope and quality of their customer relations management (CRM).

Research also needs to address information handling in sophisticated IMLS, Intelligent manufacturing and Logistics Systems designs, with trace-ability as a key concern. Manufacturing control systems already have the 
potential to address this issue. But this problem needs to be brought to the surface and to the interface, requiring additional solutions that transpire over networks and markets (e.g., Ceroni and Nof, 2005).

\subsection{Scalability, increasing costs, coordination, and market-based resource allocation}

Today, a key problem is lack of tools and platforms to test and validate IMLS developments on realistic problems, both in terms of size of the manufacturing system itself, and the thoroughness of the evaluation.

Concerning advanced manufacturing control, there are conceptual designs that address the major research issues at least in principle (e.g., Valckenaers, 2005). The complexity of these system designs makes formal proof of their performance and capabilities infeasible and impractical.

Therefore, an environment is required in which the research and development community can program and retrieve emulated test-cases of realistic size and complexity; in other words, design concepts need to be tested on real-world factories, in emulation. Moreover, the evaluation must respond to industrial requirements. Such requirements typically imply that test-runs must cover several months of realistic production.

Today, toy test-cases and token evaluations are the norm; this needs to be remedied. Evidently, the desired manufacturing systems need to be properly specified to allow drawing hard conclusions from test runs. For instance, a manufacturing control system design must randomize parameters and decisions as a default. The IMS Network of Excellence (IMS-NOE, 2004) has started to implement such an evaluation environment. It is available for advanced manufacturing control and supply network coordination. Such testing and evaluation platforms will enable researchers and developers to generate more accurate proof-of-concepts for their design results with normal levels of development efforts and resources.

Another key problem is the need for better and deeper understanding of scalability and robustness. These system's features are typically achievable only through designs that address issues of emergency, contingency, and self-repair/self-organization. These design methods cannot forego the ability to explicitly stipulate how the system will behave over a significantly larger variety of operating conditions and ranges. The analogy in human organizations is to replace explicitly prescribed procedures ("cook-book" rules) by empowering the people performing the work. It is well known that such empowerment would yield superior results, given adequately trained and qualified personnel. This shift toward empowered elements in intelligent systems needs further investigation, producing deeper insight on how this shift can be implemented and what measured benefits can be expected. In other words, better understanding of the concepts of emergence and self-organization are needed, especially from the perspective of designing such systems and synthesis of their interactions.

\subsection{Demand for customized products, model complexity, and automation reliability and dependability}

Embedding distributed technical intelligence (data / information processing, storage, and communication) into field automation has been largely experimented in order to enable actuation and measurement systems interoperability. In addition, its purpose is to ensure control, maintenance, and technical management system 
integration (Lung et al., 2001). Another major technological challenge for the development of distributed embedded systems is to guarantee both the reliability and the temporal predictability of the underlying software and hardware infrastructures. Such infrastructure must be flexible enough to easily accommodate the requirements imposed by new, emerging applications and services.

Investigation of distributed, embedded control and automation systems confirms the limits of the traditional centralized-architecture with hierarchical-model control-approaches. The two main shortcomings are (a) the inability to meet distribution requirements in automation, and (b) the inability to meet the goal of standardizing object-automation oriented approaches to design distributed automation architectures. Nevertheless, no specialization of UML, the de-facto industrial Unified Modeling Language, is efficient enough to describe and validate the behavior of such largely distributed automation systems.

The fast paced development of computer-based controllers impacts strongly on manufacturing systems dependability. Johnson (2004) outlines the emerging threat that software dependability issues may limit further automation progress at the enterprise level, in spite of very high dependability at the unit operation level (Fig.

2). The dependability issue is associated with scalability, because with increased distributed yet inter-dependant modules (agents), errors and conflicts are inevitable and automated error-detection-prevention-recovery is mandatory (Huang et al., 2000).

In a similar way, the increasing use of networked control systems within factories and enterprises can increase or decrease systems dependability, depending on the principles by which networks have been designed and setup. Ethernet TCP/IP-based networked control systems and protocols, for instance, simplify the access to process data, and therefore enable new distributed monitoring, diagnosis and maintenance functionalities. However a question immediately arises: Can the increase in communication and control traffic coming from these new functionalities still comply with the reactivity constraints required for the application? If it is not the case, how can we route and manage this new and intensive traffic? Moreover, that kind of networked control systems impacts on security by providing new opportunities to disturb or to damage the systems.

[Insert Fig. 2 here]

\subsection{Life-cycle management, critical large scale infrastructure, and security}

Ecological constraints should strongly influence and shape the future evolution of industries. The legal, ethical, strategic and operational decisions must satisfy these constraints perhaps by modification of the cost functions in different decision levels. The increased complexity of systems, information uncertainty and individual decision subjectivity can all lead to outcomes that would sometimes seem to be contradictory or wrong. To illustrate the variety of problems to be met over the Life Cycle Chain Management; an example of production, distribution and recycling of technical goods, may point to the control of the following activities: a) product design, b) material or components requirements, c) production / assembly, d) logistic / delivery, e) repairing and re-using, and f) recycling: collection, disassembly, parts or material re-use or disposal. 
Various industrial and non-industrial systems (energy systems, water systems, transportation and telecommunication networks, banking, finance and insurance organizations, emergency and health services, government institutions) represent large-scale critical infrastructure that provides essential utilities and services for the business/manufacturing processes and people that are becoming ever more dependent on them. Their operation, requested to be continuously and smoothly available, may be affected by natural and technical hazards and catastrophic failures. Increasingly, in recent years, these critical systems are also threatened by terrorism.

\section{RECENT ACCOMPLISHMENTS/TRENDS}

\subsection{Control and automation techniques}

\section{Digital enterprise technology}

Digital enterprise technology (DET) can be defined as the collection of systems and methods for the digital modeling of the global product development and realization process in the context of lifecycle management (Maropoulos, 2002). Six main technical areas are considered for realizing digital enterprises:

- distributed and collaborative design

- $\quad$ process modeling and process planning

- $\quad$ production equipment and factory modeling

- digital to physical environment integrators

- enterprise integration technologies

- manufacturing automation over networks.

Information and communication technologies enable the potential flexibility and reconfigurability of highly automated manufacturing plants (e.g., Fogliazza, 2004). The value-adding by strong collaborative integration between mechanical, automation and software engineering is enabled by encapsulating practical skills into mechatronics components. This software/hardware solution in industrial automation systems has been addressed by Vyatkin et al. (2005) with standardized object-oriented automation engineering.

\section{Multi-agent manufacturing control}

To overcome inflexibility and rigidity associated with the traditional hierarchical control of manufacturing systems, a hybrid (heterarchical) approach has been proposed. It represents a highly distributed form of control, implemented by a system of independent cooperating processes or agents without centralized or explicit direct control.

Agents may be defined as hardware-software, or software only entities that perceive their environment through sensors and act upon it through their effectors. Consequently, they must also be capable of interpreting perceptions, reasoning, and choosing actions autonomously and in ways suited to achieving their intended goals. 
To operate reliably in unknown, partially known, and dynamic environments, they must also possess mechanisms to learn and adapt their interactions with the environments. In some applications they are required to be mobile and move or access different places or parts of their operating environments. Moreover, agents may be expected to be persistent, rational, and goal-seeking, and in order to work in groups, able to communicate and collaborate.

Agent technology is considered an important approach for developing distributed manufacturing systems. Agent-based manufacturing, a.k.a. Holonic manufacturing systems (HMS) consist of autonomous, intelligent, flexible, distributed, co-operative and collaborative agents (holons). The PROSA reference architecture for HMS identifies three types of basic holons, i.e., resource, product, and order holons. Staff holons are foreseen to assist basic holons in performing their work. One of the most promising features of the agent-based approach is that it represents a transition between hierarchical and heterarchical systems.

Cooperation (by information sharing) and collaboration (by task and information sharing), error prevention and conflict resolution are key issues in agent-based systems. Negotiation-based algorithms/ protocols are mostly used where schedule generation is a recursive, iterative process with announce-bid-award cycles based on market-like mechanisms (e.g., Anussornnitisarn et al., 2005).

The order agent announces the tasks to be accomplished, usually one by one, following the process-plan associated with the given order. Having received task announcements, resource agents develop and submit bids according to their local state variables.

Several simulation frameworks for agent-based manufacturing systems have been developed, (e.g., at the PRISM Center, and at the Computer and Automation Research Institute). The objective in bid evaluation procedures can be to minimize production costs, time, and service quality factors. The objective function can be dynamically adjusted on the basis of the system state and external conditions, resulting in different control strategies and system performance. Naturally, there are variations of the above procedure. Order- (or part-) driven, and resource- (machine-, cell-, enterprise-) driven techniques can be distinguished based on who creates the announced bids and allocates tasks and resources. More advanced e-Work support-systems consider also look- ahead scheduling with a longer, possibly varying horizons, multi-echelon and multi-partner conflict resolution considerations.

\section{Bio-inspired coordination and control}

Several novel approaches for coordination and collaboration control in "artificial life" production by multi-agent systems are techniques inspired by biological control. For instance, Stigmergy is an indirect coordination tool in insect society, e.g., ant colonies, where hints from global information are made available locally by pheromones. Such efficient animal-animal interactions have been adapted for coordinating agents and holons. The goal is to reduce overloads on individual ants (and holons), so that they are not exposed to the complexity and dynamics details of each situation, by using minimal useful markings (Hadeli et al., 2004). Hence, their communication 
burden and task overloads can be minimized. The objective of such approaches is to significantly lower efforts compared with unconstrained, open market-based solutions approaches (Kumara et al., 2002).

Bio-inspired realization has included virtual ants as mobile software agents (bots); message-based interactions among agents and robots; and control-measures, such as the viability and autonomy of agents, similar to living creatures survivability and independence. It has been observed that open market-based and bio-inspired approaches represent two complementary ways for multi-agent coordination and control, especially in complex organizations (societies).

\section{Adaptation and learning in multi-agent control}

Learning and other forms of adaptation are essential in production control and automation techniques, and can be categorized as follows:

- Centralized learning (or isolated learning) refers to approaches which are entirely executed by single, completely independent agents, and exclude any interaction with other agents.

- Decentralized learning (or interactive learning) involves several agents and is executed by joint and coordinated interaction among the learners.

Adaptation is useful in market-based resource allocation processes. The adaptation procedure can be a centralized approach by which each resource agent locally adapts its behavior to achieve a more profitable position in the agent society. The feedbacks are represented by changes in local utilization parameters and bid awarding, and/or rejection reactions issued by the order agent. Each resource agent incorporates a rule-base by which it can locally decide on the cost factor to be applied for an announced task. The preconditions of these rules are the utilization of the resource and the ratio between the won and lost bids which are stored locally for each agent in the table of machine abilities and history.

Simulation studies at different labs repeatedly demonstrate that the major advantage of adaptation-by-agents is a significantly more rational allocation of tasks and more balanced use of resources. Specifically, cost-base performance measures, such as maximum tardiness, makespan at minimal cost, and maximum service level proved to be better with cost-factored, agent-base adaptation protocols.

\section{Neurodynamic programming and simulated annealing in multi-agent-based control}

An important aim is to decrease the cost of computing in schedule control. This aim can be accomplished by several techniques, as follows:

- decreasing the communication load of order agents by partly assigning their tasks to resource agents, thus further parallelizing the scheduling and the resource allocation;

- $\quad$ decreasing the number of mobile agents (e.g., virtual ants) to be sent to other resources;

- improving agents' actions in given situations/states by artificial neural network (ANN) based learning; 
- estimating the remaining processing times of jobs together with their most appropriate routes through the resources by reinforcement learning;

- balancing between exploration and exploitation in the system by using simulated annealing; and, as a result, of the above sub-goals, to

- implement multi-agent control, which can manage internal and external changes and disturbances, offer any-time solutions which can be improved when longer planning time is available, and finally, is feasible from computational point of view.

The system represents a three-level decentralized learning scheme combining neurodynamic programming (reinforcement learning + neural network) and simulated annealing (Monostori et al., 2004). Analysis results have demonstrated the ability to contribute significant improvements in system performance, with benefits of distributed control.

\section{State and trends of multi-agent control}

Recently, research on applying multi-agent systems in manufacturing and logistics has produced many valuable results. However, various obstacles for deployment in industry remain. A recent survey by Marik (2005) addresses the state of industrial applications of agent-based technology. It realizes that traditional, centralized approaches are inadequate for coping with high complexity and practical requirements for robustness, generality and reconfigurability in advanced manufacturing control and automation, production management, planning and scheduling. Often, these obstacles require multi-disciplinary solutions, for instance, the manufacturing and logistics system design and the manufacturing control are both conceived to offer flexibility, robustness, scalability and cost-effectiveness.

In response, advanced designs for multi-agent manufacturing control have emerged. However, a definitive proof-of-concept requires validation of the developments described above in industrial settings. Initial steps to provide the missing links have been developed already and key elements of validating the solutions, e.g., suitable emulation technology, are under development.

\subsection{Manufacturing plant automation}

The manufacturing enterprise is intensively deploying a host of hardware/software automation/ information technologies (Ollero, et al., 2003). It is a scientific and technological response to the increasing challenge posed by changing societal environment, which is pulled by increasing demands for customization of both goods and services, as desired by customers.

The resulting automation model is a wide network of automata which is challenging researchers and developers to achieve synchronic integration (in time) of: (1) plant and shop-floor process-controls (robotics, assembly, machining ...) (2) plant-wide information-control systems, and (3) diachronic integration (through time) of products' life-cycle over the manufacturing supply and demand chain. 
Web-enabled technologies can strengthen distributed automation in manufacturing (e.g., Banaszak and Zaremba, 2003). But further advancement requires a form of technical intelligence that goes beyond the transformation of simple data through information, to knowledge. Such intelligence needs to be embedded both in manufacturing systems' components, and within the products themselves. It will play a prominent role as the pivotal technology that is necessary to meet cost-effective agility, flexibility, and responsiveness in emerging manufacturing and logistics.

The complexity of efficiently deploying automation with interoperability and autonomy for manufacturing plant control and production management is challenging (e.g., industry-led international IMS (2004)). Researchers world-wide are attempting to define and develop the next generation of open, modular, reconfigurable, maintainable, dependable and safe manufacturing systems.

Among many rationales, trends and experiments, it is argued that ABMS (Agent-Based Manufacturing Systems), also called HMS (Holonic Manufacturing System) can be the unifying technology if implemented with PPE (Product-Process Engineering). This combined approach is needed for all product-driven control and management issues, which emerge in the competitive and mass-customized manufacturing era.

\section{Production \& logistics automation over Manufacturing Networks}

The state of the art and challenges of collaborative e-manufacturing for production and logistics (Nof, 2003) and Cooperative Manufacturing and Design and Manufacturing Modeling Issues (Kopacek et al., 2005) emphasize that e-manufacturing is highly dependent on the efficiency of collaborative human-human and Human-machine e-work. Furthermore, complementary information \& control problems in B2M (Business to Manufacturing) systems indicate the strong link between interoperability and benchmarking issues to improve manufacturing efficiency. Interoperability deals with reference models for both vertical (synchronic) integration and with horizontal (diachronic) integration. In addition, Interoperability deals with ubiquitous computing technologies to enable unique product identification and properties. The purpose is to ensure the coherence between the physical flows of goods and the related information flows of services throughout the products life-cycle. An important challenge is the need for traceability, e.g., for warranty and for security concerns.

\section{Hybrid/discrete event systems in manufacturing automation}

Manufacturing systems are hybrid by nature, because their modeling and control requires the combination of both continuous and discrete event-based models Zaytoon (2005). The development of systematic methods dealing with issues related to modeling, specification, analysis, verification, control synthesis, and implementation is of high interest to engineers of manufacturing systems as hybrid systems in industry. Such development still challenges both computer and automation scientists. Applications of design and control synthesis of DES and Petri nets-based approaches focus mainly on shop floor plant controls, although work on applying formal approaches to deal with Hybrid/DES modeling throughout time have emerged for the MES (Mfg. Execution Systems) level. This trend should continue to better cope with the lack of DES modeling 
approach for product-driven control. Such control is useful in enabling formal implementation of auto-ID technology for life-cycle product-instance traceability.

Promising applications of formal techniques for e-MES issues formally incorporate shop floor controls into plant-wide information-control systems (Fig. 3). They enable 'on the fly' response, such as rescheduling of product routes and manufacturing processes reconfigurability.

[Insert Fig. 3 here]

Communication continues to be an essential enabler of industrial automation. Real-time distributed embedded systems and networked controlled systems increase the impact of networking on manufacturing automation. At the same time, they introduce risks because networks could become Achilles' heels if not properly controlled (Neumann, 2005).

The advantage of networked control systems is in their ability to integrate all new technologies, such as wireless networks, embedded systems, nomad components, and electronic tags. This networking enables us to meet new requirements for mobility, modularity, on-line control and diagnosis, decentralization and distribution, autonomy, redundancy, and remote maintainability.

A major industrial communication challenge is how to relate multilevel communication architectures. It is necessary to unify plant networking with Ethernet, including the same deterministic features now available with fieldbus technology for the shop floor level. This unification opens up a new field of applications for intelligent control techniques in modeling, evaluation and optimization of the communication system behavior within distributed automation architectures.

[Insert Fig. 4 here]

As an example, Fig. 4 depicts an application of FDI/FTC techniques for networked, controlled systems. It should improve safe control and monitoring of such complex automation systems and their global reliability, dependability and availability by dynamically accommodating the network performance. It can also help in the reconfiguration of network components for adapting to application changes and for the delivery of expected quality of service.

\section{Dependable manufacturing systems control}

Several new trends have been noticed in the role of formal methods for improving automation software dependability. Johnson (2004) and others have used effective formal methods to specify, and then test and verify manufacturing and logistics systems industrial controls. Dependable controls impact directly upon availability, safety and security. A related trend is the growing importance of safety/ dependability-related standards for the design of industrial controllers. These standards may be domain dependant (specific standards for railway transport, power plants, etc.) or may cover a wider scope, to introduce a safety life-cycle model and the concept of SIL (Safety Integrity Level). Dependability has becomes a major concern, because current economic constraints mandate increasing availability whilst society demands safer, lower risk technological controls. These trends require more accurate safety and dependability analyses. The main issues being addressed by 
researchers in this area include use of formal or semi-formal analysis and synthesis methods for design,

implementation and validation of:

- $\quad$ system components and communication systems;

- $\quad$ analysis and synthesis with industrial size cases;

- $\quad$ impact of networked control systems on manufacturing systems dependability;

- improvement of faults forecasting with formal temporal analysis (by introduction of temporal logic in faults forecasting methods);

- reconfigurable systems design and mode management;

- $\quad$ metrics for dependability, safety and security.

Dependability analysis, as shown in recent research, is increasingly important, but it must be carried out with a system engineering view, seeking system performance optimization and cost-effectiveness, rather than merely control performance optimization (Erbe, 2003; Morel et al., 2004).

\subsection{Collaborative control through integration and networking}

Networked enterprises rely, to a large extent, on enterprise integration and enterprise modeling techniques. The objective is to improve overall performance through the networked organization (e.g., see Fig. 5) despite higher levels of dispersion and wider geographic separation of the participants.

Enterprise Integration (EI) consists of breaking down organizational barriers to improve synergy within the enterprise so that business goals are achieved in a significantly more productive and efficient way.

Enterprise Modeling (EM) is the art of externalizing enterprise knowledge which adds value to the enterprise, and needs to be shared. It consists in building models of the structure, behavior and organization of the enterprise.

EM is a pre-requisite to EI, while EI is primarily a matter of business process coordination with cooperative decision-making. Thus, there is a need for better process management and for more integration within individual enterprises and among networks of enterprises (Molina and Bell, 2002). The integration concept of providing quickly the right information at the right place at the right time in the right format throughout the enterprise is therefore evolving. Enterprise Integration now concerns (Vernadat, 2002):

- Efficient business process management, integration and coordination;

- Team collaboration supported by Computer supported collaborative work (CSCW) for concurrent design and engineering activities;

- Increased flexibility throughout the company;

- Product life-cycle management throughout the existence of a product and service;

- Interoperability of Information Technology solutions, systems and people to face environment variability in a cost-effective way. 
Among all these issues, process management, integration and coordination remain the most challenging ones because of their knowledge intensive nature (including hard problems of dealing with semantic unification), and the need for sound negotiation mechanisms among executing agents.

The following areas have been defined as the core for success in next generation manufacturing:

- Adaptable, integrated equipment, processes, and systems that can be readily reconfigured;

- Sustainable manufacturing processes that minimize waste in production and energy consumption;

- Innovative processes to design and manufacture new materials and components;

- Biotechnology for manufacturing;

- System synthesis, modeling, and simulation for all manufacturing operations;

- Technologies that can convert information into knowledge for effective decision making;

- Product and process design methods that address a broad range of product requirements;

- Enhanced human-machine interfaces;

- Educational and training methods that would enable the rapid assimilation of knowledge;

- Software for intelligent systems for collaboration.

All of these areas are strongly related to the concepts of Enterprise Modeling and Integration (EMI), and therefore it is important to foster the application of EM/EI concepts to support the generation of new technological solutions.

Thanks to recent advances in information and communication technologies (ICT), the manufacturing world is moving from highly data-driven environments to a more cooperative information/knowledge-driven environment, taking into account more of the enterprise know-how, common-sense, and application semantics. This trend has a number of consequences in the integrated enterprise and the implementation of networked enterprises (e.g., Chen et al., 2001). Table 1 (at the end of this report) summarizes how the different challenges can tackle the challenges faced by the next generation manufacturing systems, including the following:

\section{Physical System integration, application integration, and business/knowledge integration}

\section{Legacy system integration}

3. What has to be modeled and integrated in an enterprise?

Business processes to be integrated and computer-controlled first need to be formalized in a certain way, including the objects they use, handle or process, information accessed or generated, resources required for their execution and responsibilities and authorities required for their management and control. Hence, the enterprise model is useful as a semantic unification mechanism, or knowledge mapping mechanism, built by applying principles and tools of a given enterprise modeling method (Panetto et al., 2003). Semantic concept definitions in the model can be expressed in the form of ontology, i.e. using a shared, neutral knowledge representation format.

[Insert Fig. 5 here]

\subsection{Control methods applied to extended enterprises and large-scale critical infrastructure}

At the present state of technology, we can claim that Enterprise Modeling (EM) is a reality in many large companies. Enterprise Engineering practices are developing and force enterprises to consider adopting 
systematic engineering procedures, mainly based on models (Molina and Medina, 2003). Enterprise Integration

is still evolving and currently it relies mostly on advanced computer networks, the world-wide web and Internet, integration platforms and data exchange formats. Systems interoperability, however, is still very weakly addressed compared to the real needs and standard interaction and exchange protocols are still to be developed and accepted.

Part of the problem is that both EM and EI are ignored by Small \& Medium Enterprises (SMEs). On their own, SMEs have little motivation to accept these techniques. Interestingly, the situation changes when they wish to participate in a supply network. SMEs must then quickly adapt EMI technology and tools, which they have to use for efficient interactions with their larger-enterprise clients and suppliers. These technologies would better penetrate and serve any kind of enterprises under the following conditions:

1. There is a common vision on what enterprise modeling really is and there is an international consensus on the underlying concepts for the benefit of business users.

2. There is a standard, user-oriented, interface in the form of a unified enterprise modeling language (UEML) based on the consensus to be available in all commercial modeling tools.

3. There are practical enterprise modeling and simulation tools, commercially available, considering function, information, resource, organization, and financial aspects of an enterprise.

4. The tools include considerations of human factors, exception handling, and process coordination for collaboration.

5. Simulation tools need to be easily configurable, distributed, and agent-based.

6. There are reliable design patterns and model-based components available as commercial building blocks to design and reengineer large-scale systems with plug-and-play solutions.

These are some of the challenges yet to be solved in order to extend interoperable manufacturing and logistics enterprises.

Life cycle management in sustainable manufacturing and logistics systems

The concepts and approaches for analysis and control of complex systems have been useful for solving unique problems in this area, particularly, for critical large-scale infrastructure systems (Gheorghe, 2004). Unlike manufacturing enterprise-oriented emphasis on economic and business considerations and priorities, infrastructure problems are shared by all world societies, and objectives combine economic, business, government, and long-term sustainability concerns. Effective hierarchical and decentralized decision system organization and methods have been helpful for managing not only the technical processes involved, but also the information and social processes influencing people and global issues.

Life Cycle Management initiatives require a global approach. The objective is to guarantee the coherence of the individual and local decisions along the entire life cycle chain of events, and in the global context. In other words, local and regional decisions have to harmonize with overall systems' goals. The development of new conceptual approaches in this area opens the way for replacing and reusing certain traditional automatic control 
techniques, which incorporate the emerging abilities in information, communication, and decision processing (Filip et al., 2002). Efforts in applying Life Cycle Management concepts benefit from the similarity with the broad spectrum of processes in the technical, biotechnological, and managerial areas. This similarity may further help spread the research results accomplished so far.

Control and automation support in large scale, complex industrial and other systems has also begun to benefit from methods and tools traditionally used to prevent catastrophic situations. Tools have been developed to diminish vulnerability, control losses and recover from disasters. Multilevel control systems and their modern implementations as intelligent, multivalent systems have been developed successfully, for instance, for early warning sensors and networks. Predictive models and decision support systems under uncertainty for detecting and handling real-time crisis situations, e.g., emergency security and safety events, are also being considered. In the context of large scale complex systems, a serious challenge is the lack of tools for the solution of realistic problems. Examples of recent accomplishments include broadening the scope of control design under information structure constraints (Šiljak and Zečević, 2004), autonomous decentralized systems (Ahmed, 2004), collaborative Petri nets (Hsieh, 2004), and supply chain coordination (Luh and Feng, 2003). These tools will be extended to integrated/embedded control, distributed control over communication networks, discrete-event systems and networks, and autonomous systems to help solve manufacturing and logistics problems.

\section{FORECASTS}

\subsection{Next generation manufacturing systems}

The results of a study carried out in the United States for establishing the visionary manufacturing challenges for 2020 defined six grand challenges for manufacturers. They are considered grand challenges because they represent significant gaps between current practices and the emerging vision of manufacturing in the $2020 \mathrm{~s}$ (National Research Council, 1998). These grand challenges are:

1. Achieve concurrency in all operations.

2. Integrate human and technical resources to enhance workforce performance and satisfaction.

3. "Instantaneously" transform information gathered from a vast array of diverse sources into useful knowledge for making effective decisions.

4. Reduce production waste and product environmental impact to "near zero."

5. Reconfigure manufacturing enterprises rapidly in response to changing needs and opportunities.

6. Develop innovative manufacturing processes and products with a focus on decreasing dimensional scale.

In addition to the six grand challenges, the Next Generation Manufacturing Systems (NGMS) will be more strongly time-oriented while still focusing on cost and quality. A NGMS will need to satisfy the following fundamental requirements, all intrinsically dependant on systems control and automation:

- Enterprise integration,

- Distributed organization,

- Heterogeneous environments, 
- Interoperability,

- Open and dynamic structure,

- Cooperation,

- Integration of humans with software and hardware,

- Agility,

- Scalability, and

- Fault tolerance.

4.2 e-Work

e-Work is defined as collaborative, computer-supported, and communication enabled operations in highly distributed organizations of humans/ robots/ autonomous systems. Currently, e-Work enabling technologies in computing and communication are rapidly being developed. Fig. 6 depicts some of the scope differences between e-Work and e-Business. The main reason to distinguish the focus on e-Work is the realization that there are certain common principles in the design of effective e-Work, without which manufacturing, production, logistics, and other e-activities cannot succeed (Nof, 2003). Modern production and logistics systems will continue to depend on communication and telecommunication. Future research, design and implementation of e-Work will focus further on the realization of the e-Work theory, models and methods for specific applications.

[Insert Fig. 6 here]

From research on agents, rapid development of agent system and human-agent integration to assist interaction processes, such as business workflow, automated negotiation and conflict resolution, will lead the agent-based manufacturing and logistics systems into the mainstream information technology solutions.

In the research area of protocols, more complex coordination processes, such as multi-participant negotiation processes, group decision mediation, and conflict management processes will be developed. In addition, the dynamic characteristics of the protocol which acts or reacts to the stochastic nature of distributed environments will be of increasing interest.

Future research in the workflow area will focus on complex interactions for more effective, responsive integration, leading to better collaboration results. In addition, workflow control will not only guide the process, but will also involve detecting and solving errors before or as soon as they occur.

\subsection{Integration, coordination and collaboration}

Future research in the area of collaboration and integration modeling will develop decentralized decisionmaking tools by distributed and autonomous team members who have different priorities and objectives, and formulation of resolutions (service agreements) among distributed collaborators (Fig. 7). Challenges in humancomputer interaction ( $\mathrm{HCI}$ ) can provide further extension not only to explore the installed body of information, but also to discover new knowledge via intensive information exchange, similar to the brainstorming process among humans.

[Insert Fig. 7 about here] 
In areas of CIM, Computer Integrated Manufacturing \& Management, there are two emerging research trends: (1) Distributed support tools that govern the information flow among distributed manufacturing units that must act coherently under time, budget, manufacturing and environmental constraints, (2) The infusion of MEMS and nano-sensors to collect and to handle dependable information for more intelligent real-time control and decision making in active process control systems. Both of these thrusts will benefit significantly from already available wireless communication and nano-technological advances.

In the future, research will intensively address also the area of real-time decision making, execution, and conflict management. Without discoveries in this direction, effective relations among collaborators across widely distributed supply network will not be possible.

\subsection{Networked, distributed decision support (NDSS)}

Research areas on distributed decision support systems mainly categorize into development of decision models, distributed control systems, and collaborative problem-solving. Future research in decision models will focus further on interaction-based decision models with distributed knowledge sources, and human interactions, which would allow the decision structures to be adaptive and more responsive.

Distributed control system will provide functions and services with higher level of autonomy, such as networks for multi-enterprises, where each enterprise continues to hold its own goal and agenda, but can compromise to achieve faster satisfactory common goals. Similarly, in distributed robotic teams, cooperation requirement planning will be integrated with collaborative execution of tasks

Collaborative problem solving approaches will have to open up the possibility of collaboration among looselycoupled entities, where less mutual benefits are acceptable, or even required among the collaborators. This ability will be particularly useful for smooth integration and coordination despite cultural, geographical, and political differences which exist in world-wide manufacturing alliances.

\subsection{Active middleware}

In the future, active middleware services will target the very large scale computing platforms which have characteristics of highly heterogeneous, autonomous, and distributed components, beyond the typical enterprise network. Studies on active middleware combine mainly the fields of Grid computing, distributed information systems (DIS), and knowledge-based systems (KBS). The Grid computing area will enable the development of service applications which will explore the potential of the Grid computing paradigm in both scientific and business applications.

Distributed information systems will be more interactive with users in order to acquire and extract knowledge as they evolve in distributed information environments. To serve the complex needs of users, a major challenge in DIS is the analysis and control of ripple effects when one or several nodes in the distributed network fail. Security methods in DIS will be implemented to detect and provide the means to handle and prevent any 
damages that could be caused by intrusion at any point of the system, to assure total system performance integrity.

Finally, future research in KBS will focus on integrating KBS with other technologies to assist a human user or a group of users in making better decision. The integration will be especially helpful in large scale distributed information systems, and for complex unstructured problems involving high levels of uncertainty.

\section{CONCLUSIONS}

The way people and systems operate, work, communicate, and collaborate is being transformed by e-Work. Hence, understanding how to model, design and control effective e-Work is fundamental to productivity and competitiveness of future manufacturing and logistics systems. Models of e-Work have been developed to address design and automation issues, from interaction to coordination, conflict resolution and error recovery, and management of complex e-Work production and service environments. Design, control and decision tools and methods have been developed for this modeling, with the objective of understanding the emerging requirements, limitations, and potential capabilities of e-Work, e-Mfg., and e-Logistics. Modeling challenges include enhancements of models by agent-based, market-based, machine learning, and bio-inspired approaches, to include further and better e-functions. Often, such development has depended on emerging Internet, Intranet, Grid, and related technologies. Nano-technology is also transforming sensor and automation solutions. Other challenges posed by ever-increasing networking of organizations include the evaluation and assessment of new measures, such as collaboration-ability, conflict prevention-ability, and error detection-ability.

Based on extensive studies of e-Work and e-Manufacturing systems, discoveries of several design principles have emerged in four areas:

- Cooperation requirement planning

- Task parallelism

- Error and conflict handling

- e-Work, e-Manufacturing, and e-Logistics new effectiveness measures.

Effective e-Work is fundamental to e-Manufacturing and e-Logistics. Enabling services to decouple applications from the computer and communication layers can augment human work significantly by performing many tasks in parallel, by software and hardware agents, thus reducing the information overload and task overload currently imposed on human workers. In the future, based on evolving ICT, systems will be developed with inherent collaborative support tools in large-scale complex environments.

Several open questions remain: How best can people be educated and trained for work in the collaborative eenvironment? Will workers and managers be willing to trust the results obtained and delivered by the agents' work? Will we, as designers, researchers, and workers accept computer-supported negotiations as part of our activities in the future? The design, modeling, validation and implementation of effective control and automation will play an important role in addressing these issues. 


\section{ACKNOWLEDGMENT}

The authors wish to thank the many contributions of the members of the IFAC Technical Committees and Technical Board, who have contributed significant ideas for the development of this report. Thanks also to the reviewers who helped us improve the quality of this presentation. Mostly, each of us wishes to thank our colleagues and graduate students in our respective institutes, without whom all the good ideas and knowledge may not have been created.

\section{REFERENCES}

Ahmed, I., (2004). Towards the next level of abstraction - The autonomous decentralized systems - An overview. Studies in Informatics and Control, 13(4), Dec., pp. 295-304.

Anussornnitisarn, P., Nof, S.Y., and Etzion, O. (2005). Decentralized control of cooperative and autonomous agents for solving the distributed resource allocation problem, Int. J. Prod. Economics, 98(2), pp. 114-128.

Banaszak, Z. and Zaremba, M. (Eds.) (2003). Special issue on Internet-Based Distributed Intelligent Manufacturing Systems, Journal of Intelligent Manufacturing, 14(1).

Ceroni, J.A., and Nof, S.Y., Eds. (2005) Production research: facing the challenges of the new millennium, Special Issue, Int. J. Prod. Economics, 98(2).

Chen, D.,Vallespir B. and Doumeingts G., (2001). Man, Decision-making, Control and Performance: A complementary view to process-oriented approaches, Proceedings of IFAC - IMS workshop, Poznan, Poland, pp. 61-66, April.

Divoux, T., Giannopoulos, N., Roy, R., Nunez, M-J., De Togores, A.R., and Malo, P., (2005). Web Services: An Interoperability Solution In Extended-Virtual Enterprises, Proceedings of INCOM'04, Salvador, Brazil.

Erbe, H.H., (2003). Technologies for Cost Effective Automation in Manufacturing, IFAC Professional Briefs, pp. 1-32.

Filip, F.G., Donciulescu, D.A. and Filip, Cr.I., (2002). Towards intelligent real-time decision support systems for industrial milieu, Studies in Informatics and Control, 11(4), Dec., pp. 303-311.

Fogliazza, G., (2004). How Information Technology Enables The Potential Flexibility And Re-Configurability Of Highly Automated Manufacturing Plants, Proceedings of INCOM'04, Salvador, Brazil, April.

Gheorghe, A.V., (2004). Risks, vulnerability, sustainability and governance: a new landscape for critical infrastructures, International Journal of Critical Infrastructures, 1(1), pp. 118-124.

Hadeli, Valckenaers, P., Kollingbaum, M., Van Brussel, H., (2004). Multi-Agent Coordination and Control Using Stigmergy, Computers in Industry, 53, pp. 75-96.

Hsieh, F.-S., (2004). Analysis of a class of controlled Petri nets based on structural decomposition. Proceedings of IFAC Symp. LSS2004, Osaka, Japan, July

Huang, C.Y., Ceroni, J.A., and Nof, S.Y., (2000). Agility of Networked Enterprises - Parallelism, Error Recovery and Conflict Resolution, Computers in Industry, 42(2-3), pp. 275-287.

IMS (2004), http://www.ims.org

IMS-NOE (2004), http://www.ims-noe.org

Ishii, K., Ichimura, T., and Mihara, I. (2005). Information behavior in the determination of functional specifications for new product development, Int. J. Prod. Economics, 98(2), pp. 262-270. 
Johnson, T.L., (2004). Improving Automation Software Dependability: A Role for Formal Methods (Plenary), Proceedings of INCOM’04, Salvador, Brazil, April.

Kopacek, P., Pereira, C.E., and Morel, G. (Eds.) (2005). Information Control Problems in Manufacturing, Proceedings of INCOM'04, Salvador, Brazil, IFAC publication/Elsevier Sciences, 2 Volumes.

Kumara, S.R.T., Lee, Y-H. and Chatterjee, K., (2002). Distributed Multiproject Resource Control: A MarketBased Approach, Annals of the CIRP, 51(1), pp. 367-370.

Luh, P. and Feng, W., (2003). From manufacturing scheduling to supply chain coordination: The control of complexity and uncertainty. Proceedings of the 4th International Conference on Control and Automation, Montreal, Canada.

Lung, B., Neunreuther, E. and Morel, G. (2001). Engineering process of integrated-distributed shop floor architecture based on interoperable field components. International Journal of CIM, 14(3), 246-262.

Marik, V., (2005). Industrial Applications of the Agent-Based Technology, Proceedings of INCOM'04, Salvador, Brazil.

Molina A. and Bell R., (2002). Reference Models for the Computer Aided Support of Simultaneous Engineering, Int. J. CIM, 15(3), pp. 193-213.

Molina, A., and Medina, V., (2003). Application of Enterprise Models and Simulation Tools for the evaluation of the impact of best manufacturing practices implementation, Annual Reviews in Control, 27(2), pp. 221228.

Monostori, L., (2003). AI and Machine Learning Techniques for Managing Complexity, Changes and Uncertainties in Manufacturing, Engineering Applications of Artificial Intelligence, 16(4), pp. 277-291.

Monostori, L., Csáji, B.Cs. and Kádár, B., (2004). Adaptation and learning in distributed production control, Annals of the CIRP, 53(1), pp. 349-352.

Morel, G., Panetto, H., Zaremba, M. and Mayer, F., (2003). Manufacturing enterprise control and management system engineering: rationales and open issues. Annual reviews in Control, 27, pp. 199-209.

Morel, G., and Grabot, B., (Eds.), (2003). Intelligent Manufacturing. Special issue of Engineering Applications of Artificial Intelligence, 16 (4).

Morel G., Merry D., Leger JB., Lecomte T. (2004); Proof-Oriented Fault-Tolerant systems engineering : rational, experiments and open issues; Plenary Lecture; Proceedings of the 7th IFAC symposium on Cost Oriented Automation; Gatineau, Canada, 6-9 June.

Maropoulos, P.G., (2002). Digital Enterprise Technology - Defining Perspectives and Research Priorities, Proceedings of CIRP Seminar on Digital Enterprise Technology, September, Durham, UK, pp. 3-12.

National Research Council, (1998). Visionary Manufacturing Challenges for 2020, National Academy Press. (http://search.nap.edu/ readingroom/books/visionary/index.html)

Neumann, P., (2005). Communication In Industrial Automation-What Is Going On? Proceedings of INCOM'04, Salvador, Brazil.

Nof, S. Y., (2003). Design of effective e-Work: review of models, tools, and emerging challenges, Production Planning and Control, 14(8), pp. 681-703.

Nof, S.Y., (2004). Collaboration Principles for Networked Production and Logistics (Plenary), Proceedings of IFAC MCPL, Management \& Control of Production and Logistics, Santiago, Chile, November. 
Ollero, A., Morel, G., Bernus, P., Nof, S., Sasiadek, J., Boverie, S., Erbe, H. and Goodall, R., (2003). Milestone report of the Manufacturing and Instrumentation coordinating Committee: From MEMS to Enterprise Systems. IFAC Annual Reviews in Control, 26, pp. 151-162.

Panetto H., Berio G., Petit M. and Knothe T., (2003). Enterprise integration semantics issue. Proceedings of the International NIST/NSF Workshop on Semantics Distance, NIST, November, Gaithersburg, Maryland, USA.

Ramírez-Santaella, A. and Molina, A., (2004). A. Multihead and Web Technology for the Implementation of a Manufacturing Execution System, Proceedings of INCOM’04, Salvador, Brazil, April.

Qiu, R. and Russel, D., (2004). A formal model for incorporating shop floor controls into plant information systems. International Journal of Advanced Manufacturing Technology Production Research, 23, pp. 47-57.

Valckenaers, P., Cavalieri, S., Germain B. S., Verstraete, P., Hadeli, T.S., and Van Brussel, H., (2005). A Benchmarking Service for the Manufacturing Control Research Community, Proceedings of INCOM'04, Salvador, Brazil, April.

Vernadat, F.B., (2002). Enterprise Modeling and Integration (EMI): Current Status and Research Perspectives, Annual Reviews in Control, 26, pp. 15-25.

Vyatkin, V., Hanisch, H.-M., and Bouzon, G., (2005). OOONEIDA Community in IMS, Open Object-Oriented Modeling and Validation Framework for Modular Industrial Automation Systems, Proceedings of INCOM’04, Salvador, Brazil.

Zaytoon, J. and Gueguen, H., (2005). Analysis of Hybrid Systems: State of the Art, Proceedings of INCOM'04, Salvador, Brazil.

Šiljak, D.D. and Zečević, (2004). Control of large scale systems: Beyond decentralized feedback.

Proceedings of LSS2004, Osaka, Japan, July. 
Figure legends

Fig. 1. Scope of functional challenges/solutions and emerging trends for solution approaches

Fig. 2. Scenario of Software Complexity Growth and System Availability Decline (Johnson, 2004)

Fig. 3. Integration-ready Structured Adaptive Supervisory Control model (Qiu and Russell, 2004)

Fig. 4. Quality of Service (QoS) of a Networked Controlled System Tolerant to Faults (Divoux et al., 2005)

Fig. 5. Multi-Head Manufacturing Execution Display using Web-browsers (Ramírez-Santaella and Molina, 2004)

Fig. 6. e-Work is fundamental to e-Business, e-Commerce, e-Mfg., e-Logistics, and other e-activities (just as work is fundamental to business, commerce, and other activities) (Nof, 2004)

Fig. 7. Exchange and collaboration over a distributed coordination network, DCN. TA=Task agent;

RA=Resource agent; T=Time; Bid=Bid for task/resource; Qprice=Quoted price; QLT=Quoted lead-time;

VTA, VRA=Viability function of TA or RA (Anussornnitisarn et al., 2005)

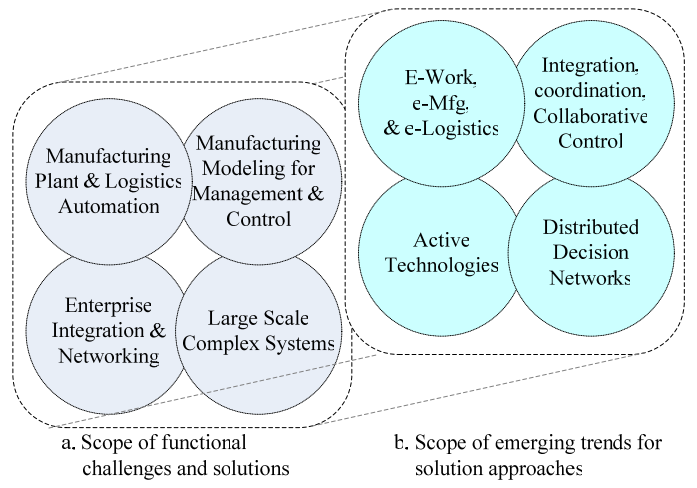

Fig. 1. Scope of functional challenges/solutions and emerging trends for solution approaches

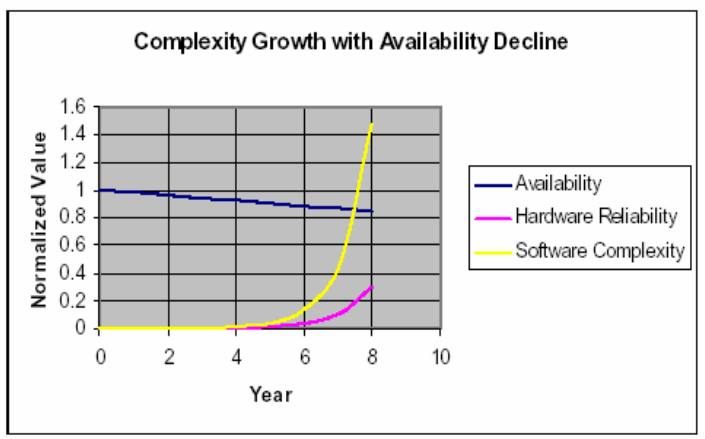

Fig. 2. Scenario of Software Complexity Growth and System Availability Decline (Johnson, 2004) 


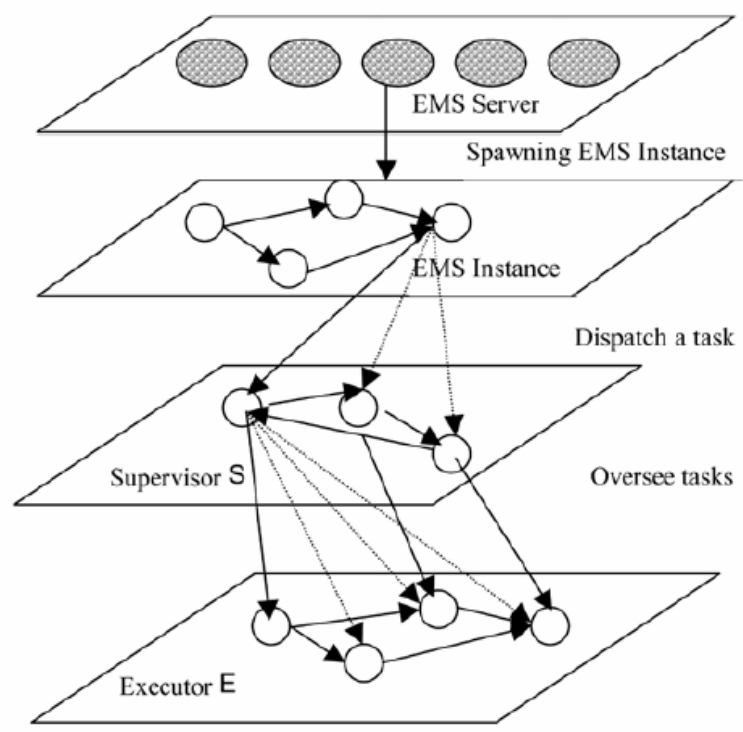

Fig. 3. Integration-ready Structured Adaptive Supervisory Control model (Qiu and Russell, 2004)

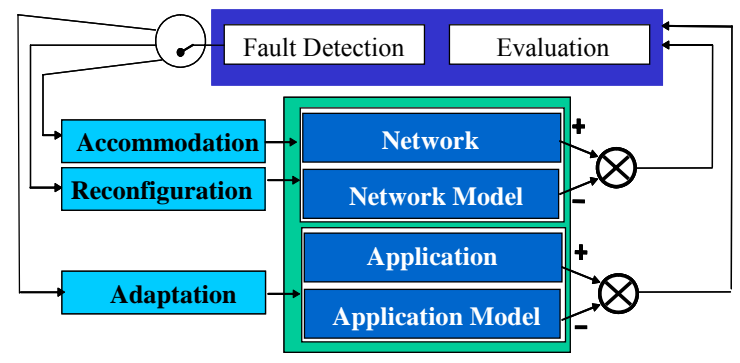

Fig. 4. Quality of Service (QoS) of a Networked Controlled System Tolerant to Faults (Divoux et al., 2005)

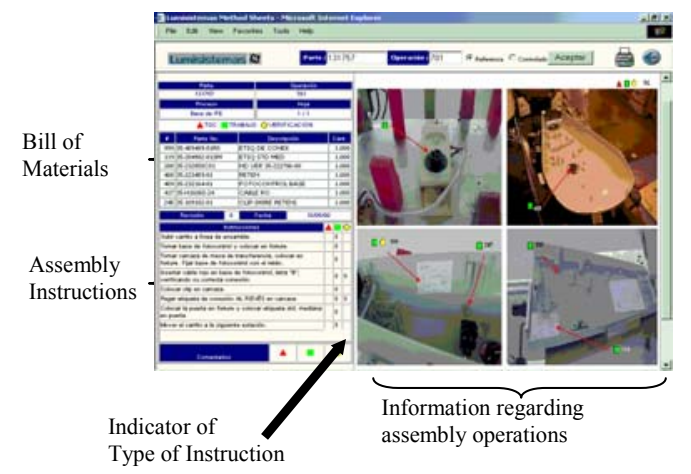

Fig. 5. Multi-Head Manufacturing Execution Display using Web-browsers (Ramírez-Santaella and Molina, 2004) 


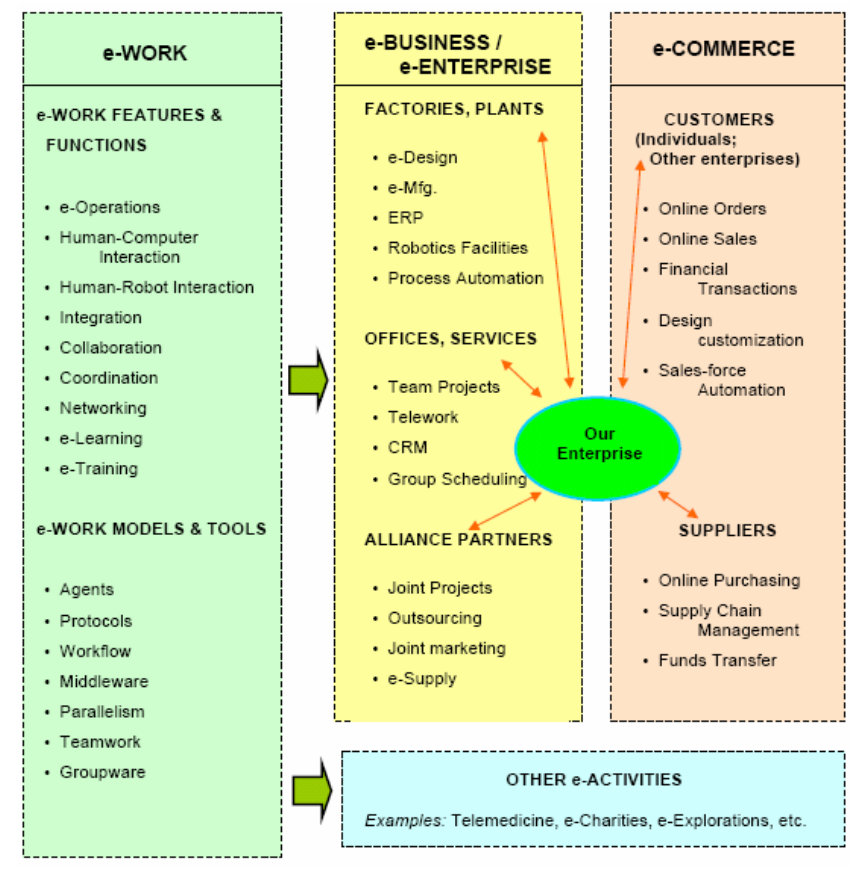

Fig. 6. e-Work is fundamental to e-Business, e-Commerce, e-Mfg., e-Logistics, and other e-activities (just as work is fundamental to business, commerce, and other activities) (Nof, 2004).

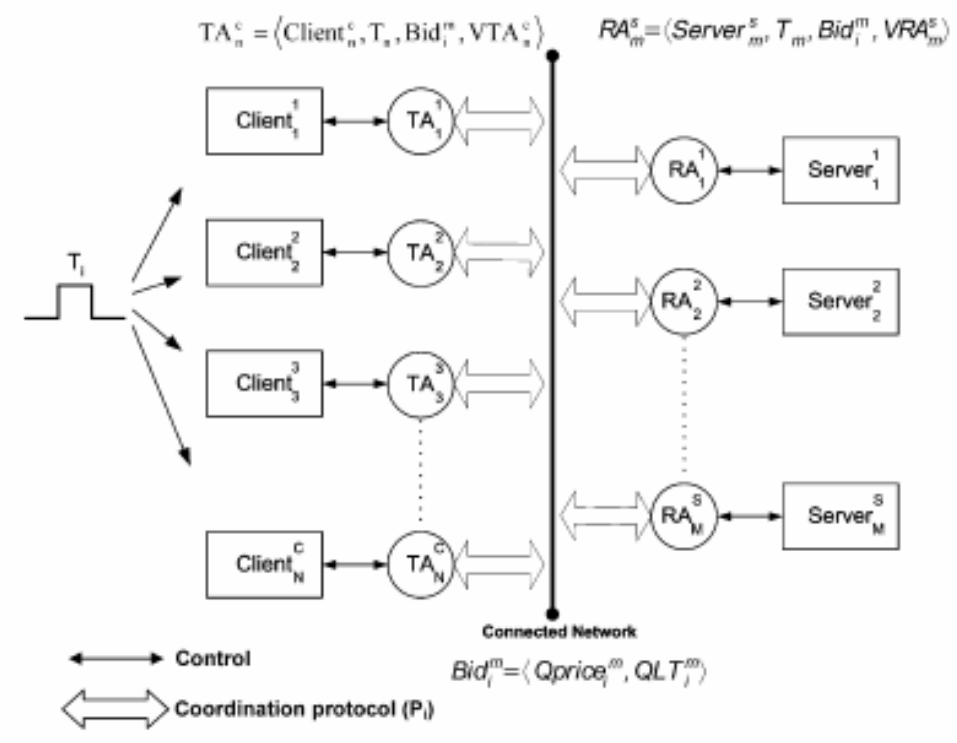

Fig. 7. Exchange and collaboration over a distributed coordination network, DCN. TA=Task agent;

$\mathrm{RA}=$ Resource agent; T=Time; Bid= Bid for task/resource; Qprice=Quoted price; $\mathrm{QLT}=$ Quoted lead-time;

VTA, VRA=Viability function of TA or RA (Anussornnitisarn et al., 2005) 
Table 1. Manufacturing Challenges and Enterprise Integration proposals

\begin{tabular}{|c|c|c|c|c|}
\hline CHALLENGES & BUSINESS & KNOWLEDGE & APPLICATIONS & $\begin{array}{l}\text { COMMUNICATIONS } \\
\text { (ICT) }\end{array}$ \\
\hline $\begin{array}{l}\text { Grand Challenge } 1 \text {. Achieve } \\
\text { concurrency in all operations }\end{array}$ & $\begin{array}{l}\text { - Business and strategy models } \\
\text { - Evaluation tools for decision } \\
\text { making }\end{array}$ & $\begin{array}{l}\text { - Knowledge about business } \\
\text { processes and operations } \\
\text { (functions, information, } \\
\text { organization and resources) } \\
\text { - Knowledge about core } \\
\text { competencies (resources } \\
\text { based view) } \\
\text { - Knowledge based simulation }\end{array}$ & $\begin{array}{l}\text { - Software to simulate operation to } \\
\text { see parallelism and concurrency } \\
\text { - Standards } \\
\text { - Tools for monitoring and control of } \\
\text { parallelism and concurrency }\end{array}$ & $\begin{array}{l}\text { - Standards } \\
\text { - Reliable communication } \\
\text { networks }\end{array}$ \\
\hline $\begin{array}{l}\text { Challenge 2. Integrate human } \\
\text { and technical resources to } \\
\text { enhance workforce performance } \\
\text { and satisfaction. }\end{array}$ & $\begin{array}{l}\text { - Enterprise measurement } \\
\text { systems (e.g. Balanced Score } \\
\text { Card) } \\
\text { - Enterprise trust systems } \\
\text { - Compensation systems based } \\
\text { on enterprise performance } \\
\text { measures }\end{array}$ & $\begin{array}{l}\text { - Description of Skills, Core } \\
\text { Competencies, Organization } \\
\text { roles and Knowledge assets } \\
\text { - On line resources availability } \\
\text { and capacity }\end{array}$ & $\begin{array}{l}\text { - Integration of Enterprise } \\
\text { Applications (ERP,MES, SCADA, } \\
\text { Factory Automation Systems) } \\
\text { - Workflow management systems } \\
\text { (WfMS) } \\
\text { - Computer Supported Cooperative } \\
\text { Work (CSCM) }\end{array}$ & $\begin{array}{l}\text { - Open platforms and } \\
\text { architectures } \\
\text { - Human Computer } \\
\text { Interaction applications } \\
\text { - Friendly User Interfaces }\end{array}$ \\
\hline $\begin{array}{l}\text { Challenge 3. "Instantaneously" } \\
\text { transform information gathered } \\
\text { from a vast array of diverse } \\
\text { sources into useful knowledge } \\
\text { for making effective decisions. }\end{array}$ & $\begin{array}{l}\text { - Integration of business } \\
\text { information } \\
\text { - Networked enterprises } \\
\text { - Ontologies } \\
\text { - Consistent enterprise-wide } \\
\text { decision-making structure }\end{array}$ & $\begin{array}{l}\text { - Interoperability of models } \\
\text { - Standards (KIF, KQML) } \\
\text { - Ontologies }\end{array}$ & $\begin{array}{l}\text { - Standards } \\
\text { - Interfaces } \\
\text { - Interoperability } \\
\text { - Data Warehouse-Mining } \\
\text { - Decision support software }\end{array}$ & $\begin{array}{l}\text { - Standards } \\
\text { - Interfaces } \\
\text { - Interoperability }\end{array}$ \\
\hline $\begin{array}{l}\text { Grand Challenge } 4 \text {. Reduce } \\
\text { production waste and product } \\
\text { environmental impact to "near } \\
\text { zero." }\end{array}$ & $\begin{array}{l}\text { - Standards } \\
\text { - International Regulations } \\
\text { - Optimization Models } \\
\text { - Sustainable development } \\
\text { models } \\
\text { - lean and clean production } \\
\text { paradigms }\end{array}$ & $\begin{array}{l}\text { - Reference models } \\
\text { - Total quality control } \\
\text { - Total quality maintenance }\end{array}$ & $\begin{array}{l}\text { - Operations control software, } \\
\text { Monitoring software } \\
\text { - TQC support software } \\
\text { - Preventive maintenance planning } \\
\text { system }\end{array}$ & $\begin{array}{l}\text { - Operations control } \\
\text { hardware } \\
\text { - Benchmarking and } \\
\text { Performance measures } \\
\text { systems }\end{array}$ \\
\hline $\begin{array}{l}\text { Grand Challenge } 5 \text {. Reconfigure } \\
\text { manufacturing enterprises rapidly } \\
\text { in response to changing needs } \\
\text { and opportunities. }\end{array}$ & $\begin{array}{l}\text { - Reference Models and } \\
\text { architectures } \\
\text { - New manufacturing paradigms } \\
\text { (holonic manufacturing, } \\
\text { intelligen agents, } \\
\text { decentralised and } \\
\text { autonomous production } \\
\text { cells/unit) }\end{array}$ & $\begin{array}{l}\text { - Reference models } \\
\text { - Ontologies } \\
\text { - Polyvalence of human } \\
\text { operators } \\
\text { - Model-based manufacturing } \\
\text { and control }\end{array}$ & $\begin{array}{l}\text { - Component based enterprise } \\
\text { applications } \\
\text { - Modular systems } \\
\text { - Components based software } \\
\text { solutions (Plug in/Plug out) } \\
\text { - Simulation software } \\
\text { - Standards }\end{array}$ & $\begin{array}{l}\text { - Interoperatibility } \\
\text { - Standards }\end{array}$ \\
\hline $\begin{array}{l}\text { Grand Challenge } 6 \text {. Develop } \\
\text { innovative manufacturing } \\
\text { processes and products with a } \\
\text { focus on decreasing dimensional } \\
\text { scale. }\end{array}$ & $\begin{array}{l}\text { - Make/Buy Strategies, } \\
\text { Reference Models (ATO, } \\
\text { CTO, BTO) } \\
\text { - Virtual enterprise paradigm }\end{array}$ & $\begin{array}{l}\text { - Integrated Product and } \\
\text { Process Development } \\
\text { - Product Life Cycle } \\
\text { Management } \\
\text { - Innovative design theories }\end{array}$ & $\begin{array}{l}\text { - Product Data Management / } \\
\text { Product Life Cycle Management } \\
\text { - Advanced Planning Systems } \\
\text { - Supply Chain Management } \\
\text { - Logistic Management Systems } \\
\text { - Knowledge Based Engineering }\end{array}$ & $\begin{array}{l}\text { - Wireless local area } \\
\text { network } \\
\text { - Web-based applications } \\
\text { - Smart Cards applications } \\
\text { - Nanotechnology and } \\
\text { MEMS }\end{array}$ \\
\hline
\end{tabular}


Shimon Y. Nof, Professor of Industrial Engineering at Purdue University (since 1977), has held visiting positions at MIT and Universities in Chile, EU, Hong Kong, Israel, Japan, and Mexico. Director of the NSF and industry supported PRISM Center for Production, Robotics, and Integration Software for Manufacturing \& Management (since 1991); he is a Fellow of IIE, Secretary General and President Elect of IFPR (International Foundation of Production Research), and current Chair of IFAC Committee on Manufacturing \& Logistics Systems. His current research focus: Collaborative automation and robotics; Collaborative e-Work and e-Business support systems; Design of nanosystems with real-time decision networks. He has published over 350 articles on production engineering and information/robotics engineering and management, and is the author/editor of ten books in these areas, including Handbook of Industrial Robotics first and second editions, International Encyclopedia of Robotics and Automation, and Industrial Assembly. In 1999 he was elected to the Purdue Book of Great Teachers, and in 2002 he was awarded the Engelberger Medal for Robotics Education. Nof has also had over eight years of experience in full-time industry and government positions.

Gérard Morel is currently co-director of CRAN, the Research Centre for Automatic Control of Nancy (http://www.cran.uhp-nancy.fr), which is an associate unit of the CNRS (National Centre for Scientific Research) and a common lab of the UHP (University Henri Poincaré, Nancy I) and of the INPL (Polytechnics National Institute of Lorraine). He has directed about $25 \mathrm{PhD}$ Theses and published over 150 articles in the area of 'systems and automation engineering'. He holds research positions in national and international networks of research and is currently Europe Editor of the International Journal of Intelligent Manufacturing. He has also served in several positions in IFAC, as expertevaluator for the European Commission, and is currently expert for the French Ministry of Research and Education and the CNRS. As Professor at the UHP, he is Director of a master degree on 'Systems Engineering'.

Prof. László Monostori has been with the Computer and Automation Institute of the Hungarian Academy of Sciences (SZTAKI) since 1977, now he serves as Deputy Director Research. He is also the head of the Department on Production Informatics, Management and Control at the Budapest University of Technology and Economics. He is an Active Member of the International Academy for Production Engineering (CIRP) and Chairman of the Scientific-Technical Committee on Optimisation of Manufacturing Systems; Full Member of the European Academy of Industrial Management (AIM); Vice President of the International Society of Applied Intelligence (ISAI); Chairman of the Technical Committee on Manufacturing Modelling, Management \& Control, International Federation of Automatic Control (IFAC), and Chairman of the Technical Committee on Technical Diagnostics, International Measurement Confederation (IMEKO). He is Chairman of the Editorial Committee of CIRP Annals, Associate Editor of Computers in Industry, CIRP Journal of Manufacturing Systems, IEEE Transactions on Automation Sciences and Engineering (T-ASE), and member of the editorial boards of other international scientific periodicals. For his research achievements published in nearly 300 publications resulted in more than 800 independent citations and for his development activities - among others - the Dennis Gabor Prize was given to him in 2004.

Professor Dr. Arturo Molina is Dean of the School of Engineering and Architecture of Monterrey Institute of Technology (Tecnológico de Monterrey), Campus Monterrey. He was a visiting professor at UC Berkeley at Mechanical Engineering Department during his Sabbatical year (2004/2005). He received his PhD degree in Manufacturing Engineering at Loughborough University of Technology, England in July 1995, his University Doctor degree in Mechanical Engineering at the Technical University of Budapest, Hungary in November 1992, and his M.Sc. degree in Computer Science from ITESM, Campus Monterrey in December 1992.<> Professor Molina is member of the National Researchers System of Mexico (SNI-Nivel II), Mexican Academy of Sciences, IFAC Chair of Technical Committee WG 5.3 Enterprise Integration and Enterprise Networking, and member of IFIP WG5.12 Working Group on Enterprise Integration Architectures and IFIP WG 5.3 Cooperation of Virtual Enterprises and Virtual Organizations.

Prof. Florin Gheorghe Filip (www.ici.ro/ici//homepage/filipf.html ) was born in Bucharest, Romania, in 1947. He received his MSc and Ph.D. degrees in Control Engineering from the Technical University "Politehnica" Bucharest in 1970 and 1982, respectively. He has been with the Research Institute for Informatics $-\mathrm{ICl}$ (www.ici.ro) since 1970. Prof. Filip was elected as a member of the Romanian Academy of Sciences ( RAS- www.acad.ro ) in 1991 and was elected as the vice-president of RAS in 
2000 and re-elected in 2002. His main scientific interests are: large -scale systems control, decision support systems, IT applications in manufacturing and cultural institutions. Prof. Filip is the chair of the IFAC TC 5.4. He authored/co-authored about 200 papers published in scientific journals and contributed volumes. He is the author/co-author of six monographs and the editor/co-editor of eight contributed volumes. 